\title{
Clinical Outcome of Meningitis and Its Risk Factors Among Children Admitted in Debre Markos Referral Hospital Pediatric Ward, Northwest Ethiopia,2019
}

Hailemariam Abiy ( $\square$ hailemariamabiy74@yahoo.com )

Debre Markos University https://orcid.org/0000-0002-2985-0805

Zelalem Shiferaw

Debre Markos University

Yilkal Tafere

Debre Markos University

Research

Keywords: Bad outcomes, Meningitis, Risk, Children

Posted Date: June 22nd, 2020

DOI: https://doi.org/10.21203/rs.3.rs-36044/v1

License: @ (i) This work is licensed under a Creative Commons Attribution 4.0 International License. Read Full License 


\section{Abstract}

Background:Meningitis remains a major cause of mortality and morbidity in patients in many countries of the world including Ethiopia. This study aimed to assess clinical outcomes and associated risk factors of meningitis among children who were admitted to Debre Markos Referral Hospital from January 2017 to December 2018.A backward stepwise multivariable logistic regression was applied with $95 \%$ confidence interval of odds ratio (OR) andstatistical significance less than $0.05 p$-value were taken as cut off value.

Methods:A retrospective cross-sectional study was conducted. The study includesAll pediatric meningitis 211 cases from the age of one month to fourteen who were admitted due to meningitis in Debre Markos Referral Hospitalfrom January 2017 to December 2018.Data were entered, cleaned, and analyzed using SPSS for Windows, version 20.

Results:The study showed that $18.9 \%$ of children with meningitis developed bad outcomes. In this study, children who were a worse clinical condition at admission 6 times more likely to develop bad outcomes [AOR=6.321 $(2.121,18.837)]$ and having a seizure at admission almost 19 times more likely to develop bad outcomes [AOR=18.953(6.677, 53.799)].

Conclusions:About one in five children with meningitis developed bad outcomes. The health care team should due attention to improving care for patients with severe conditions at admission and seizures were the alarming signs for poor outcomes in children.

\section{Background}

Meningitis, termed arachnoiditis or leptomeningitis, is an inflammation of the membranes that surround the brain and spinal cord, thereby involving the arachnoids, the pia mater, and the interposed cerebrospinal fluid (CSF). The inflammatory process extends throughout the subarachnoid space around the brain, spinal cord, and ventricles [1].

It has been divided into septic meningitis and aseptic meningitis. Bacterial or septic meningitis is an acute meningeal inflammation secondary to a bacterial infection that generally evokes a polymorph nuclear response in the CSF. Aseptic meningitis refers to a meningeal inflammation without evidence of pyogenic bacterial infection, usually accompanied by mononuclear pleocytosis. Aseptic meningitis is subdivided into two categories: nonbacterial meningeal infections (typically viral or fungal meningitis), and noninfectious meningeal inflammation from systemic diseases (such as sarcoidosis), neoplastic disease (leptomeningeal carcinomatosis or neoplastic meningitis), or drugs [2].

Bacterial meningitis is characterized by severe headache, fever, intolerance to light and sound, and rigidity of muscles, especially those of the neck. The central nervous system (CNS) inflammatory reaction from bacterial meningitis may result in decreased consciousness, seizures, raised intracranial pressure, and stroke [3]. The most common bacteria responsible for meningitis are Streptococcus pneumoniae, Neisseria meningitides (N.meningitidis), and Listeria monocytogenes and Haemophilus influenzae. In children, meningococcal, Haemophilus influenzae type b (Hib), and Streptococcus pneumoniae are the most common causes [4].

Meningitis caused by bacteria is a medical emergency. The therapeutic goal is to initiate antibiotic therapy within 60 minutes of patient arrival in the emergency room. In patients suspected of having bacterial meningitis, CSF should be obtained for cultures and empirically antimicrobial therapy should be initiated without delay $[5,6]$.

A region in sub-Saharan Africa, extending from Ethiopia in the east to the Gambia in the west and containing 15 countries with > 260 million people, is known as the "meningitis belt" because of its high prevalence of endemic diseases with periodic epidemics caused by N.meningitidis [7,8] Pediatric meningitis is a life-threatening illness in children [9]. Beyond the neonatal period, since the routine use of Hib, conjugate pneumococcal, and conjugate meningococcal vaccines in the United States, the incidence of meningitis has dramatically decreased[10,11]. Until recently, meningitis was a greatly feared infectious disease because it struck and killed many of its victims among children with mortality rates of up to $30 \%$. Moreover, $20-50 \%$ of pediatric patients who survive the infection have serious and permanent neurological sequelae, which include deafness, mental retardation, and learning impairment, sensory-motor deficits, seizure disorders, and cerebral palsy. The incidence of neurologic sequelae of bacterial meningitis in children has not significantly improved over the last decade. Hearing impairment is the most common neurological sequel following meningitis $[1,9]$.

Although antibiotics are often administered before the laboratory results of CSF culture and sensitivity, however, there is limited information available on the risk factors and clinical outcomes of meningitis. Therefore, this study aimed to identify the risk factors and clinical outcomes of meningitis among children admitted with meningitis to Debre Markos Referral Hospital, Northwest Ethiopia.

Page 2/10 
1. Objectives

General objective

To assess clinical outcomes and associated risk factors of meningitis among pediatric patients who were admitted in Debre Markos Referral Hospital due to meningitis from January 2017 to December 2018 in Debre Markos, North West Ethiopia.

3. Specific objectives

1. To determine the outcomes of meningitis among pediatric patients admitted to Debre Markos Referral Hospital from January 2017 to December 2018.

2. To identify factors associated with poor outcomes of pediatric meningitis patients admitted to Debre Markos Referral Hospital from January 2017 to December 2018.

\section{Methods}

\subsection{Study area and period}

The study was conducted in Debre Markos Referral Hospital, which is located in Debre Markos town, Northwestern Ethiopia. The hospital is located $299 \mathrm{~km}$ far from Addis Ababa, the capital city of Ethiopia and an additional $265 \mathrm{~km}$ long to get Bahir Dar city of Amhara Regional state. Data collection was conducted from March 8, 2019, to April 6, 2019 G.C

\subsection{Study Design}

A retrospective cross-sectional study was conducted.

\subsection{Population}

\subsubsection{Source population}

All pediatric meningitis cases were admitted to Debre Markos Referral Hospital from January 2017 to December 2018.

\subsubsection{Study population}

All pediatric meningitis cases from the age of one month to fourteen who were admitted due to meningitis in Debre Markos Referral Hospital from January 2017 to December 2018.

\subsection{Inclusion and Exclusion criteria}

\subsubsection{Inclusion criteria}

All pediatric meningitis cases from the age of one month to fourteen years who were admitted to Debre Markos Referral Hospital from January 2017 to December 2018.

\subsubsection{Exclusion criteria}

Children admitted with a diagnosis of meningitis with incomplete medical records weren't included. The initial diagnosis of meningitis changed to others like urinary tract infection malaria and pneumonia, were not included.

\subsection{Sampling size determination and sampling techniques}

\subsubsection{Sample size determination}

The sample size $(n)$ of this study was determined based on a single population proportion ( $p$ ) formula by considering a $5 \%$ margin of error, 15\% prevalence, and 95\% confidence interval. The total sample size was 196.

\subsubsection{Sampling procedures /Techniques/}

Systematic sampling was used to assess the outcomes and associated risk factors of pediatric meningitis. All 211 pediatric meningitis patients aged from one month to fourteen years who were admitted in the study period will be taken, and 15 cases were excluded based on the criteria. 


\subsection{Data collection tool}

Data were collected from the patient files and recordings using checklists.

\subsection{Data collection procedure}

Data were collected from the secondary data which was obtained from patient files and registration books in DMRH March 8/2019April 6/2019 G.C. Data were collected by 2 health professionals who had degree holders and one supervisor who observed the data collection process.

\subsection{Data quality control}

The record was checked for its completeness using a checklist. The training was given to the data collectors and the supervisor for 1 day.

\subsection{Study variable}

\subsubsection{Dependent variables}

Clinical outcomes (Good versus Bad)

\section{- 3.9.2 Independent variables}
1. Age
2. Residence
3. Sex
4. Season
5. Vaccination

\subsection{Operational definition}

- 3.10.1 Good outcome: Good outcome means improvement without acute complications. Signs and symptoms of suspected meningitis like fever (temperature $\geq 38^{\circ} \mathrm{C}$ ) and at least one of the following meningeal signs: convulsions, bulging fontanels in children or stiff neck, poor sucking or irritability, prostration or lethargy, or petechial rash returned to normal (improved) condition after initiation of therapy

3.10.2 Bad outcome: Poor outcome comprises as death within the ward, developed acute neurologic complications: septic shock, impaired mental status, brain abscess, seizures, hydrocephalus, focal deficits (hearing loss, cranial nerve palsies, hemiparesis, or quadriparesis during treatment or at discharge, refer to a higher level care and left against medical advises with no improvement after initiation of treatment.

\section{Pediatrics}

Age less than or equal to fourteen years.

\section{○ 3.11 Data analysis}

Data were entered, cleaned, and analyzed using SPSS for Windows, version 20. To ensure the quality of data entry, it entered into two computers. Frequencies and cross-tabulations were used to summarize the data. Bivariate analysis was done for all independent variables. Associated variables with statistical significance of p-value less than 0.25 in the bivariate analysis were entered in the final multivariable logistic regression model. A backward stepwise multivariable logistic regression was applied. Lastly, an odds ratio (OR)was presented with a $95 \%$ confidence interval and the level of statistical significance was presented based on a p-value less than 0.05 .

\section{Results}

\subsection{Socio-demographic characterization}


One hundred ninety-six pediatric files were reviewed. Of the total, $125(63.8 \%)$ were males and $71(36.2 \%)$ were females. Overall, 101 (51.5\%) were between one month and one-year-old and 95 (48.5\%) were between one and fourteen years, as shown in Table 1.

Table 1

Socio-demographic characteristics of meningitis patients who were admitted in DMRH from January 1, 2017 to December 30, 2018

\begin{tabular}{|llll|}
\hline Variables & & Frequency & Valid Percent \\
\hline Sex & Male & 125 & 63.8 \\
\cline { 2 - 4 } & Female & 71 & 36.2 \\
\hline \multirow{2}{*}{ Age } & 1 month-1 year & 102 & 52.0 \\
\cline { 2 - 4 } & $1-2$ years & 22 & 11.2 \\
\cline { 2 - 4 } & 3-5 years & 33 & 16.8 \\
\cline { 2 - 4 } & 6-14 years & 39 & 19.9 \\
\hline Residence & Urban & 85 & 43.4 \\
\hline & Rural & 111 & 56.6 \\
\hline
\end{tabular}

\subsection{Possible risk factors for meningitis}

From the selected factors, $83(45.4 \%)$ completed their immunization. Among pediatric meningitis cases, $124(79 \%)$ were recorded as no sign of a nutritional problem and $72(36.7 \%)$ of them took corticosteroid drugs before the initiation of antibiotics. In most patients, 72(36.7\%) were admitted in the spring season, as shown in Table 2.

Table 2

Possible risk factors for meningitis patients who were admitted in DMRH from January 1,2017 to December 2018

\begin{tabular}{|c|c|c|c|}
\hline Variables & & Frequency & $\%$ \\
\hline \multirow[t]{4}{*}{ Season } & Winter & 30 & 15.3 \\
\hline & Autumn & 44 & 22.4 \\
\hline & Summer & 50 & 25.5 \\
\hline & Spring & 72 & 36.7 \\
\hline \multirow[t]{2}{*}{ Co-infection* } & Yes & 1 & .5 \\
\hline & No & 195 & 99.5 \\
\hline \multirow[t]{4}{*}{ Immunization status $(n=183)$} & Incomplete & 4 & 2.2 \\
\hline & Complete & 83 & 45. 4 \\
\hline & Not started & 48 & 26.2 \\
\hline & up-to-date & 48 & 26.2 \\
\hline \multirow[t]{2}{*}{ Use of corticosteroid } & No & 112 & 63.3 \\
\hline & Yes & 72 & 36.7 \\
\hline \multirow[t]{2}{*}{ Nutritional status $(\mathrm{n}=157)$} & Malnourished & 33 & 21 \\
\hline & No sign of malnutrition & 124 & 79 \\
\hline *Co-infection with AIDS & & & \\
\hline
\end{tabular}

\subsection{Clinical conditions and physical findings}


Regarding clinical presentation at admission, 61(31.1\%) were a worse condition, 164(83.4\%) cases had vomiting, 57(29.1\%) cases had seizures, and most of them $170(86.7 \%)$ presented with a complaint of fever.

Regarding physical findings, 84 (42.9) of them had respiratory distress, 82(41.8\%) were lethargic, and 25(12.8) were unconscious. Most patients who had a fever, $127(64.8 \%)$ were febrile with a body temperature greater than or equal to $38{ }^{0} \mathrm{C}$. In all patients, $75(38.7 \%)$ and $71(28.2 \%)$ were positive for neck stiffness and Brudzinski's \& kerning's sign, respectively. Among the total cases of the study, $6(3.1 \%)$, 10(5.1\%), and 3(1.5\%) had bulged fontanel, nerve palsies, and paralysis, respectively.

\subsection{Investigations}

From one hundred ninety-six patients, cerebrospinal fluid (CSF) analysis was done for 135(68.9\%); among them, 84(62.2\%) had confirmed meningitis. A gram stain was done for 77(57\%), and acid-fast bacilli (AFB) test was done for 55 patients there were no positive findings. From the total participants, 2 (1\%) cases were developed hydrocephalus, as shown in Table 3.

Table 3

Investigation of pediatric patients who were admitted in DMRH due to meningitis from January1, 2017 to December 30, 2018

\begin{tabular}{|c|c|c|c|}
\hline \multicolumn{2}{|l|}{ Variables } & \multirow{2}{*}{$\begin{array}{l}\text { Frequency } \\
135\end{array}$} & \multirow{2}{*}{\begin{tabular}{l|}
$\%$ \\
68.9
\end{tabular}} \\
\hline CSF analysis was done & Yes & & \\
\hline & No & 61 & 31.1 \\
\hline \multirow[t]{2}{*}{ WBC in CSF $(n=135)$} & $>20$ cells $/ \mathrm{mm}^{3}$ & 84 & 62.2 \\
\hline & $<20$ cells $/ \mathrm{mm}^{3}$ & 51 & 37.8 \\
\hline \multirow[t]{2}{*}{ Gram stain Done $(n=135)$} & Yes & 77 & 57 \\
\hline & No & 58 & 43 \\
\hline \multirow[t]{2}{*}{ Gram stain result $(n=77)$} & Positive & 11 & 14.3 \\
\hline & Negative & 66 & 85.7 \\
\hline \multirow[t]{2}{*}{ protein level $(n=93)$} & protein $>1 \mathrm{~g} / \mathrm{L}$ & 83 & 89.2 \\
\hline & protein $</=1 / 0.5 \mathrm{~g} / \mathrm{L}$ & 10 & 10.8 \\
\hline Glucose level & glucose level 40 or less & 77 & 82.8 \\
\hline$(n=93)$ & glucose level > 40 mg/dl & 16 & 17.2 \\
\hline \multirow[t]{2}{*}{ AFB done $(n=135)$} & Yes & 55 & 40.7 \\
\hline & No & 80 & 59.3 \\
\hline \multirow[t]{2}{*}{ AFB result $(n=55)$} & Negative & 42 & 76.4 \\
\hline & Undifferentiated & 13 & 23.6 \\
\hline \multicolumn{4}{|l|}{ Other investigation } \\
\hline \multirow[t]{2}{*}{ Hydrocephalous } & Yes & 2 & 1 \\
\hline & No & 194 & 99 \\
\hline
\end{tabular}

\subsection{Outcomes}

Of all pediatric meningitis cases reviewed, 159 (81.1\%) had good outcomes (discharged after improvement) and 37(18.9\%), had bad outcomes (developed complication 10[5.1\%], refer to higher level of care 2[1\%], left against medical advice $17[8.7 \%]$, and death $8[4.1 \%]$ were observed).

\subsection{Factors associated with poor outcomes of meningitis}

Factors associated with poor outcome of pediatric meningitis among variables: age, corticosteroid administration, nutritional status, clinical presentation, seizure, level of temperature, level of consciousness, and respiratory distress were the clinical condition at 
admission, and seizure.

Children who were a worse clinical condition at admission 6 times more likely to develop [AOR $=6.32(2.12,18.84)]$ bad outcomes and those who had seizure 19 times more likely to develop bad outcomes $[A O R=18.95(6.68,53.80)]$ as shown in Table 4.

Table 4

Factors associated with poor outcomes of meningitis in pediatric patients who were admitted in DMRH from January1, 2017 to December30, 2018

\begin{tabular}{|c|c|c|c|c|c|c|c|}
\hline \multirow[t]{2}{*}{ Variables } & & \multicolumn{2}{|c|}{$\begin{array}{l}\text { Final outcome (Count \& } \\
\% \text { ) }\end{array}$} & \multirow[t]{2}{*}{$\begin{array}{l}\mathrm{p}- \\
\text { value }\end{array}$} & \multirow[b]{2}{*}{$\operatorname{COR}(95 \% \mathrm{CL})$} & \multirow[b]{2}{*}{$\mathrm{AOR}(95 \% \mathrm{CL})$} & \multirow[b]{2}{*}{$\begin{array}{l}\mathrm{P}- \\
\text { value }\end{array}$} \\
\hline & & Good & Bad & & & & \\
\hline \multirow[t]{2}{*}{ Age } & $\begin{array}{l}1 \text { month - } \\
1 \text { years }\end{array}$ & $89(56 \%)$ & $13(35.1 \%)$ & $0.025^{\star}$ & $0.426(0.202, .897)$ & & \\
\hline & Above 1 year & $70(44 \%)$ & $24(64.9 \%)$ & & 1 & & \\
\hline \multirow{2}{*}{$\begin{array}{l}\text { Use of } \\
\text { corticosteroid }\end{array}$} & No & $95(59.7 \%)$ & $29(78.4 \%)$ & $0.038^{\star}$ & $2.442(1.050,5.682)$ & & \\
\hline & Yes & $64(40.3 \%)$ & $8(21.6 \%)$ & & 1 & & \\
\hline \multirow{2}{*}{$\begin{array}{l}\text { Nutritional } \\
\text { status }\end{array}$} & Malnourished & $20(16.7 \%)$ & 13(35.1) & & 1 & & \\
\hline & $\begin{array}{l}\text { well } \\
\text { nourished }\end{array}$ & $100(83.3 \%)$ & $24(64.9 \%)$ & $0.018^{*}$ & $0.369(0.161,0.845)$ & & \\
\hline \multirow{2}{*}{$\begin{array}{l}\text { Clinical } \\
\text { condition at } \\
\text { admission }\end{array}$} & Worse & $43(27 \%)$ & $18(48.6 \% 0$ & $0.012^{\star}$ & $2.556(1.227,5.322)$ & $6.321(2.121,18.837)$ & 0.001 * \\
\hline & Better & $116(73 \%)$ & $19(51.4 \%)$ & & 1 & 1 & \\
\hline \multirow{2}{*}{$\begin{array}{l}\text { Level of } \\
\text { temperature at } \\
\text { admission }\end{array}$} & $>/=38$ & $97(61 \%)$ & $30(81.1 \%)$ & $0.025^{\star}$ & $2.739(1.134,6.619)$ & & \\
\hline & $<38$ & $62(39 \%)$ & $7(18.9 \%)$ & & 1 & & \\
\hline \multirow{2}{*}{$\begin{array}{l}\text { Level of } \\
\text { consciousness }\end{array}$} & Impaired & $79(49.7 \%)$ & $28(75.7 \%)$ & $0.006^{*}$ & $3.150(1.398,7.102)$ & & \\
\hline & Conscious & $80(50.3 \%)$ & $9(24.3 \%)$ & & 1 & & \\
\hline \multirow{2}{*}{$\begin{array}{l}\text { Respiratory } \\
\text { distress }\end{array}$} & Yes & $62(39 \%)$ & $22(59.5 \%)$ & $0.026^{*}$ & 1 & & \\
\hline & No & $97(61 \%)$ & $15(40.5 \%)$ & & $0.436(0.210,904)$ & & \\
\hline \multirow[t]{2}{*}{ Seizure } & Yes & $29(18.2 \%)$ & $28(75.7 \%)$ & $.000 *$ & 13.964(5.949,32.697) & $18.953(6.677,53.799)$ & 0.000 * \\
\hline & No & $130(81.8 \%)$ & $9(24.3 \%)$ & & 1 & 1 & \\
\hline
\end{tabular}

\section{Discussion}

In this study, meningitis was common from 1 month to 1 year of age, which accounted for $52 \%$ of pediatric meningitis cases. A similar study conducted in Pakistan showed that $68.3 \%$ were infants [12], and a study in Turkey showed that the highest incidence was in children 1-12 months of age.[7].

The current study indicates that $56.6 \%$ of the study participants lived in rural areas. This is different from the study conducted in Felege Hiwot Referral Hospital[13], the residents of pediatric patients were urban (67\%) and Nepal was urban (88.1\%)[14]. This may be due to demographic, socio-cultural, and economic differences between people in the study area.

This study showed that most of pediatric meningitis were admitted in the spring season, which was $36.7 \%$. A similar study conducted in Iran showed that most meningitis patients were admitted in the spring season[15]. This may be due to temperature, humidity level, pressure, wind, and dust during the season.

Malnutrition is one of the risk factors that can expose to the development of meningitis[6]. This study indicated that about $21 \%$ of the patients were malnourished. A similar study was conducted in Felege Hiwot Referral Hospital indicated that $18 \%$ of the patients were 
malnourished [13]. In the study conducted in Libya and India [8], only $0.2 \%$ and $2.4 \%$, respectively, were malnourished. This showed that there was a relatively high rate of malnutrition in the current study. This difference might be due to demographics, socio-cultural and economic differences between people in the different study areas and community awareness about childhood feeding practices in a different area.

In this study, $45.4 \%$ of the participants completed their vaccination. A similar study was conducted in the Felege Hiwot Referral hospital, and $49.4 \%$ of children completed their vaccination[13]. In contrast, in a study conducted in Turkey[7], $91.3 \%$ of the immunization status was completed. This difference might be due to community awareness about the risk factors of pediatric meningitis.

Different infections or diseases can be a risk for the development of meningitis. Among these, HIV/AIDS, tuberculosis, cerebral malaria, and sepsis are the most common. This study indicated that $0.5 \%$ of the patients were co-infected with HIV/AIDS. Research done at Felege Hiwot Referral Hospital showed that $4.5 \%$ \& $2.2 \%$ and in Nigeria, $2.1 \%$ and $4.5 \%$ were co-infected with HIV/AIDS and tuberculosis, respectively,[13,16,17]. The difference might be a variation in socio-demographic and study design.

Most of the clinical presentations and physical examinations in this study were fever (86.87\%), vomiting (83.7\%), respiratory distress (42.9\%), loss of consciousness (54.6\%), and seizure. About $28.2 \%$ had positive Brudinski \& Kerning signs, and $38.7 \%$ of them had positive neck stiffness. A similar study was done on Felege Hiwot Referral Hospital, $93.1 \%$ was febrile, $91.1 \%$ had vomiting, $22.9 \%$ were in respiratory distress, $30.7 \%$ had positive Brudinski \& Kerning signs, $28 \%$ of them had positive neck stiffness, and $59.7 \%$ patients lost their consciousness [13].

Laboratory investigations of CSF specimens in suspected cases of meningitis are extremely important for prompt diagnosis and management of patients[8]. In this study, 135(68.9\%) patients were investigated for their CSF, and among them, 84 (62.2\%) of meningitis patients had an elevated level of WBC. Similar studies were done Felege Hiwot Referral Hospital[13], and in Taiwan[18] indicated that most admitted patients tested their CSF, which was about $69.8 \%$ and $88 \%$, respectively. Among them, $98.3 \%$ and $83.8 \%$ had elevated WBC, respectively.

Gram stain examination of CSF permits rapid, accurate identification of the causative bacterium in $60-90 \%$ of patients with meningitis[8]. In contrast to this, the current research gram stain on CSF provided 11(14.3\%) meningitis pediatric patients were positive. It was less than that of Felege Hiwot Referral Hospital, which was about 32(30.2\%). The difference might be due to the variation of etiology and difference in the study area.

The outcomes of this study were good or bad. In this regard, $157(81.1 \%)$ of them were improved and discharged after improvement (good outcome) and $18.9 \%$ were a bad outcome. Among these, 10(5.1\%) developed complications, 2(1\%) referred to higher-level for brain imaging (CT scan), 17(8.7\%) left against medical advice after the clinical conditions worsened and 8(4.1\%) died. The factors that contributed to these complications were nerve palsies, 10(5.1\%) and paralysis 3(1.5\%). A similar study was conducted in Felege Hiwot Referral Hospital and Brazil, 19(10.6\%) and 2(5.7\%) had complications of cranial nerve involvement that led to an oculomotor problem (nerve palsies), and $0.6 \%$ and $2.9 \%$ were for paralysis respectively[13, 15]. Also, a study conducted in Felege Hiwot Referral Hospital showed that $15 \%$ of pediatric meningitis cases developed poor outcomes and referred to higher facility $4.5 \%$, and death $3.4 \%$ was stated thus, it was a better outcome than this study area [13]. This different outcome could be the difference in institutional capacity and other risk factors in the study area.

In this study, 29.1\% study participants developed seizures and children who had seizures were almost 19 times more likely to develop bad outcomes [AOR $=18.953(6.677,53.799)$ ] than their counterparts. Studies Felege Hiwot Referral Hospital and in Norway[19], it wasn't a determinant factor for the outcome. Because they classified seizures as a short course and prolonged seizure.

This study showed that children with the worse clinical condition at admission developed 6 times more likely to develop bad outcomes as compared to cases admitted in a better condition [AOR $=6.321(2.121,18.837)]$. This finding is similar to other studies conducted in Felege Hiwot Referral Hospital; children with a worse clinical presentation were almost 9 times more likely to develop poor outcomes [AOR $=8.779(1.599,48.192)][13]$. This is also comparable may be due to the effect of a difference in ethological and cases of demographic variation.

\section{Conclusion}

Page $8 / 10$ 
In summary, the clinical outcomes of pediatric meningitis in this study area was poorer than that in reviewed hospitals. One in five pediatric meningitis cases in this study area had a bad outcome. seizures and worse clinical conditions at admission were associated factors for poor pediatric meningitis outcomes.

\section{- 8. Recommendation}

1. Hospital and Health Department should create awareness among the health care team to give due attention to pediatric patients presenting with a worse clinical presentation at admission and seizure.

2. Health workers should create community awareness about each risk factor and early health seeking-practice to improve clinical outcomes.

3. Researchers should do further study on identification of bacterial species and antibiotic susceptibility to improve outcomes related to causative agents.

\section{Limitation Of The Study}

The study was based on secondary data (chart review) and may not display all factors that were not documented in the patient's files. There were no identified bacterial species that helped to see the outcomes related to causative agents.

\section{Abbreviations}

AFB -Acid-Fast Bacilli;AOR-AdjustedOdds Ratio; CSF -Cerebro-Spinal Fluid;CNS-Central Nervous System;DMRH-Debre Markos Referral Hospital;Hib-Haemophilus influenzae type $b$;WBC-White Blood cells

\section{Declarations}

\section{Acknowledgments}

Thanks to Debre Markos University College Health Sciences and Medicine for giving permission letter to do this research.

I would like to acknowledge the Debre Markos Referral Hospital for permitting the review of medical recordssecurely.

\section{Ethics approval and consent to participate}

It was obtained from the Ethical Review Committee of Debre Markos University College of Health Sciences. Apermission letter from Debre Markos Referral Hospital was obtained. The aim of the study was informed to the patient record office,and the information obtained will be kept confidential.

\section{Consent to publish}

"Not applicable"

\section{Availability of data and materials}

"The dataset will not be shared to protect the participants' identities"

\section{Competing of interests}

The authors declare that they have no competing interests.

\section{Funding}

"Not applicable"

\section{Author's contributions}

ZS conceived and designed the study and performed the analysis. HA participated indesigning,supervising, reviewing,and analyzing the study; and prepared this manuscript. YTfinally reviewed the design, analysis, and discussion through their critical comments at each 
step of the research.

\section{References}

1. Schuchat A, et al. Bacterial meningitis in the United States in 1995. New England journal of medicine. 1997;337(14):970-6.

2. Mace SE. Acute bacterial meningitis. Emerg Med Clin North Am. 2008;26(2):281-317.

3. Kim KS. Acute bacterial meningitis in infants and children. The Lancet infectious diseases. 2010;10(1):32-42.

4. Davison K, Ramsay M. The epidemiology of acute meningitis in children in England and Wales. Arch Dis Child. 2003;88(8):662-4.

5. Brouwer MC, Tunkel AR, van de Beek D. Epidemiology, diagnosis, and antimicrobial treatment of acute bacterial meningitis. Clin Microbiol Rev. 2010;23(3):467-92.

6. O'Donnell EP, et al., Empiric antibiotic selection for infectious emergencies: bacterial pneumonia, meningitis and sepsis. Drugs of today (Barcelona, Spain: 1998), 2009. 45(5): p. 379-393.

7. Ceyhan M, et al. A prospective study of etiology of childhood acute bacterial meningitis. Turkey Emerging infectious diseases. 2008;14(7):1089.

8. Chugh Y, et al. Study of antimicrobial sensitivity pattern of Gram-positive CSF isolates among children suffering from septic meningitis in a tertiary care hospital. J Indian Acad Clin Med. 2011;12:274-82.

9. Nigrovic LE, Malley R, Kuppermann N. Meta-analysis of bacterial meningitis score validation studies. Arch Dis Child. 2012;97(9):799-805.

10. Chang C-J, et al. Bacterial meningitis in infants: the epidemiology, clinical features, and prognostic factors. Brain development. 2004;26(3):168-75.

11. Arditi M, Ables L, Yogev R. Cerebrospinal fluid endotoxin levels in children with $\mathrm{H}$. influenzae meningitis before and after administration of intravenous ceftriaxone. J Infect Dis. 1989;160(6):1005-11.

12. Attia Bari FZ, et al. Childhood acute bacterial meningitis: clinical spectrum, bacteriological profile and outcome. Journal of the College of Physicians Surgeons Pakistan. 2016;26(10):822-6.

13. Tewabe T, et al. Clinical Outcomes and Risk Factors of Meningitis among Children in Referral Hospital, Ethiopia, 2016: A Retrospective Chart Review. Ethiopian journal of health sciences. 2018;28(5):563.

14. Modi G, et al. Bacteriological profile of pyogenic meningitis in tertiary care hospital, Ahmedabad. Natl J Med Res. $2012 ; 2(3): 313-7$.

15. Mosavi-Jarrahi A, et al., Temporal analysis of the incidence of meningitis in the Tehran metropolitan area, 1999-2005. Population health metrics, 2009. 7(1): p. 19.

16. Thinyane KH, Motsemme KM, Cooper VJL, Clinical presentation, aetiology, and outcomes of meningitis in a setting of high HIV and TB Prevalence. Journal of tropical medicine, 2015. 2015.

17. Wu H-M, et al. Clinical features, acute complications, and outcome of Salmonella meningitis in children under one year of age in Taiwan. BMC Infect Dis. 2011;11(1):30.

18. Lin W-L, et al. Analysis of clinical outcomes in pediatric bacterial meningitis focusing on patients without cerebrospinal fluid pleocytosis. Journal of Microbiology Immunology Infection. 2016;49(5):723-8.

19. Kaaresen P, Flaegstad T. Prognostic factors in childhood bacterial meningitis. Acta Paediatr. 1995;84(8):873-8. 